This document is the Accepted Manuscript version of a Published Work that appeared in final form in Langmuir, copyright $(\odot)$ American Chemical Society after peer review and technical editing by publisher. To access the final edited and published work see http://dx.doi.org/10.1021/la3035424

\title{
Instantaneous Attachment of an Ultrahigh Density of Non-thiolated DNA to Gold Nanoparticles and Its Applications
}

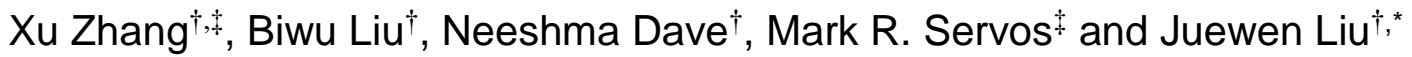 \\ † Department of Chemistry and Waterloo Institute for Nanotechnology, $₫$ Department of Biology, University of \\ Waterloo, 200 University Avenue West, Waterloo, Ontario, Canada N2L 3 G1. \\ *To whom correspondence may be addressed: liujw@uwaterloo.ca
}

\begin{abstract}
The last 16 years have witnessed the landmark development of polyvalent thiolated DNA functionalized gold nanoparticles (AuNPs) possessing striking properties within the emerging field of nanobiotechnology. Many novel properties of this hybrid nanomaterial are attributed to the dense DNA shell. However, the question of whether non-thiolated polyvalent DNA-AuNP could be fabricated with high DNA density and similar properties as its thiolated counterpart has not been explored in detail. Herein, we report that by simply tuning the $\mathrm{pH}$ of the DNA/AuNP mixture, an ultrahigh capacity of nonthiolated DNA can be conjugated to AuNPs in a few minutes, resulting in polyvalent DNA-AuNP conjugates with cooperative melting behavior, a typical property for polyvalent thiolated DNA functionalized AuNPs. With this method, large AuNPs (e.g., $50 \mathrm{~nm}$ ) can be functionalized to achieve colorimetric detection of sub-nM DNA. Further, this fast and stable DNA loading was employed to separate AuNPs of different size. We propose that a large fraction of the attached DNAs are adsorbed via one or a few terminal bases to afford the high loading capacity and the ability to hybridize with the complementary DNA. This discovery not only offers a time- and cost-effective way to functionalize AuNPs with a high density of non-thiolated DNA, but also provides new insights into the fundamental understanding of how DNA strands with different sequences interact with AuNPs.
\end{abstract}

\section{Introduction}

The interaction between single-stranded DNA (ssDNA or DNA unless otherwise specified) and gold nanoparticles (AuNPs) represents a classic example of the bio/nano interface. The molecular recognition 
and programmability of DNA have been coupled to the physical properties of AuNPs. Significant advances in biosensor development, ${ }^{1-4}$ materials fabrication, ${ }^{5-9}$ nanomedicine, ${ }^{10}$ and nanotechnology ${ }^{11}$ have already been demonstrated. To conjugate a DNA to AuNPs, the following two strategies have been employed. In the first approach, a thiolated DNA is mixed with AuNPs and a high DNA density can be achieved via a process known as 'salt aging' (Figure 1A), where salt is gradually added over 1-2 days so that an increasing number of DNA strands can be adsorbed to form stable conjugates. ${ }^{12-14}$ Recent improvements of this strategy including the use of surfactants and sonication have drastically reduced the aging time to a few hours and even very large AuNPs could be functionalized. ${ }^{14,15}$ Depending on the final salt concentration and DNA sequence, up to $~ 130$ thiolated DNA can be adsorbed on each $13 \mathrm{~nm}$ AuNP. ${ }^{14,15}$ The loading capacity could be further increased by adding a polyethylene glycol spacer between the thiol label and DNA. We recently reported the attachment of a high density of thiolated DNA in just a few minutes using a pH 3 buffer. ${ }^{16}$ Many of the unique properties of thiol-DNA functionalized AuNPs are attributed to the high DNA density (i.e. polyvalent nanoconjugate), ${ }^{11}$ including cooperative melting transition, tighter binding to complementary DNA, cell internalization, and resistance against nuclease degradation. ${ }^{17-21}$

For the second strategy, non-thiolated DNAs can be adsorbed onto AuNPs via the DNA bases. Adenine and cytosine have a strong affinity while thymine binds to gold surface weakly. ${ }^{22,23}$ The generally accepted adsorption model for this process is shown in Figure 1B, where DNA wraps around the AuNP. ${ }^{22,24-26}$ The adsorption of non-thiolated DNA has also found important applications in analytical chemistry, ${ }^{27-34}$ polymerase chain reactions, ${ }^{35,36}$ nanoparticle synthesis, ${ }^{37,38}$ and medicine. ${ }^{37,39}$ We recently reported that at neutral $\mathrm{pH}$, each $13 \mathrm{~nm}$ AuNP adsorbs just around twenty 12 -mer DNAs even after overnight incubation, ${ }^{40}$ which is consistent with the results from the literature using polyadenosine (e.g $\mathrm{A}_{20}$ ) as an anchoring block for DNA adsorption with the salt aging approach. ${ }^{41}$ This 
number is much lower than that can be achieved using thiolated DNA (up to 130 DNAs on each $13 \mathrm{~nm}$ AuNP), supporting the DNA wrapping model presented in Figure 1B.

An important question arises therefore as to whether a similarly high DNA density can be achieved using non-thiolated DNA, and if so, can similar polyvalent properties comparable to thiolated DNA/AuNP conjugates be realized. Herein, we report a surprisingly high non-thiolated DNA loading capacity achieved at low $\mathrm{pH}$ in a few minutes, suggesting a new model of DNA interaction with AuNPs (Figure 1C). DNA loading capacity, kinetics, sequence-dependent adsorption and stability were systematically studied. Characteristic polyvalent properties such as DNA-directed assembly, colorimetric detection and cooperative melting behavior were demonstrated with the non-thiolated DNA-AuNP conjugates. In addition, electrophoretic separation of AuNPs was achieved taking advantage of the high stability of such conjugates.

A

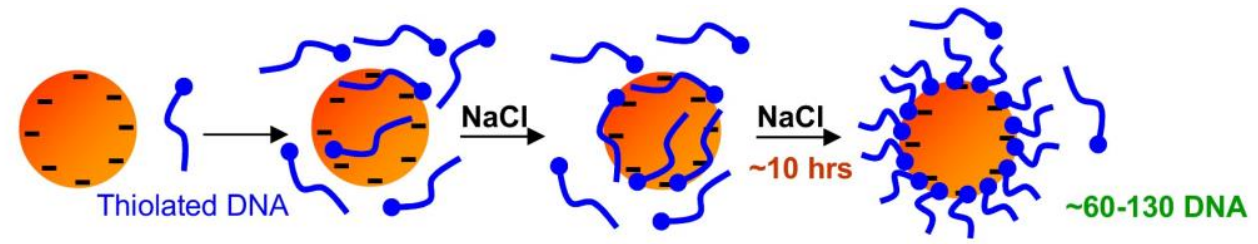

B
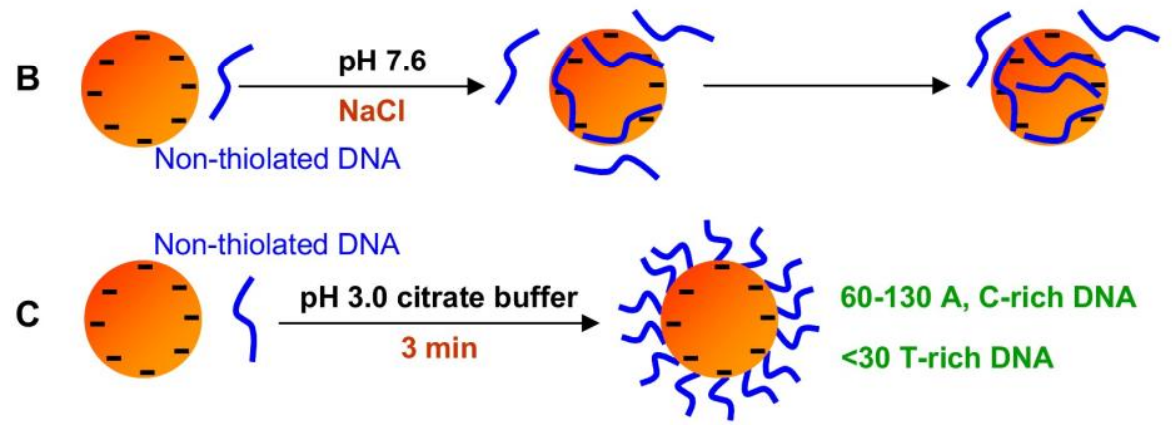

Figure 1. Schematic presentation of attaching thiolated DNA (A) or non-thiolated DNA (B) to AuNPs using the salt aging method and (C) attaching a high density of non-thiolated DNA at low pH. For nonthiolated DNA adsorption, it is generally accepted that DNA wraps around AuNPs, leading to a relatively low loading capacity (B). At low $\mathrm{pH}$, a high capacity could be achieved, suggesting a different model of DNA adsorption (C). 


\section{Results and discussion}

Ultrahigh DNA loading. To understand non-thiolated DNA loading at low $\mathrm{pH}$, DNA adsorption isotherms were measured with 6-carboxyfluorescein (FAM)-labeled $\mathrm{A}_{15}$ DNA at pH 3 (see Table 1 for DNA sequences and modifications). We found a surprisingly high DNA loading capacity of $\sim 130$ strands per $13 \mathrm{~nm}$ AuNP at a FAM-A15-to-AuNP ratio of 400:1 (Figure 2A). For comparison, only 40 FAM$\mathrm{A}_{15}$ DNAs were attached at $\mathrm{pH} 7$ (Figure 2A, inset), highlighting the effect of low $\mathrm{pH}$ for achieving a high capacity of non-thiolated DNA. At the same time, this method allows fast adsorption in a few minutes with a low salt concentration (e.g. final $\mathrm{Na}^{+}$concentration $=30 \mathrm{mM}$ in Figure $2 \mathrm{~A}$ ).

Our data could be fit to the Langmuir isotherm at both pH's (Figure 2A), where adsorbed DNA reached a plateau at high DNA concentrations. There are a few assumptions for the Langmuir adsorption model including monolayer adsorption, lack of lateral adsorbate interactions and homogeneity of the surface. It is unlikely that all the assumptions are strictly satisfied on the AuNP surface. For example, the adsorbed DNAs repel each other by electrostatic interaction and they may also attract each other by hydrogen bonding especially at low $\mathrm{pH}$. The AuNP surface is unlikely to be homogeneous either. We measured the DNA loading capacity after repeated washing the AuNPs in a pH 7.6 buffer and DNAs not directly attached to AuNPs were removed. The saturation of adsorption at high DNA concentration suggests that the most important monolayer assumption to be true.

Based on Figure 2A, the Langmuir constants for $\mathrm{pH} 3$ and $\mathrm{pH} 7$ are 0.64 and $1.6 \mathrm{DM}^{-1}$, respectively. The physical meaning of the Langmuir constant is the ratio of adsorption rate constant over desorption. If the Langmuir model were true, the overall adsorption at $\mathrm{pH} 7$ would have been even more favorably. This is clearly not the case since $~ 130$ DNAs were adsorbed at $\mathrm{pH} 3$ in a few minutes while it takes many hours to adsorb less than $40 \mathrm{DNA}$ at neutral $\mathrm{pH}$. We reason that as the density of DNA is increased, further adsorption of DNA becomes slower and this effect is more pronounced for the low $\mathrm{pH}$ 
sample since its final capacity is much higher. This comparison thus suggests that the Langmuir model may not be appropriate to describe DNA adsorption on AuNPs at low $\mathrm{pH}$.

As poly-A DNA is known to strongly interact with gold surface, we further tested the effect of nucleotide composition using FAM-T 15 and FAM-C 15 (Figure 2B). Poly-G was not tested since it is different to synthesize a long stretch of guanines. With a DNA-to-AuNP ratio of 200:1, only <30 FAMT 15 or $\mathrm{G}_{15}$ was adsorbed at $\mathrm{pH} 3$ while the number of adsorbed FAM- $\mathrm{C}_{15}$ exceeded 120 . The difference in loading capacity might be explained by the electrostatic repulsion among DNA stands as well as between DNA and citrate-capped AuNPs. Both DNA and citrate-capped AuNPs are negatively charged at pH neutral. Cytosine $\left(p K_{a}=4.2\right)$ and adenine $\left(p K_{a}=3.5\right)$ can be effectively protonated at $\mathrm{pH} 3$, thus decreasing the electrostatic repulsion and favoring DNA adsorption onto AuNP surfaces. The loading of FAM-T 15 at $\mathrm{pH} 3$ was similar to that achieved at neutral $\mathrm{pH},{ }^{40}$ consistent with the fact that thymine cannot be protonated at $\mathrm{pH}$ 3. A 12-mer DNA with random sequence (Table 1) also showed a high loading capacity of $\sim 93$ DNA per AuNP at pH 3 (Figure 2B). Therefore, a high loading capacity at low pH for non-thiolated DNA can be achieved as long as the DNA is not rich in thymine. 
Table 1. DNA sequences used in this work.

\begin{tabular}{|c|c|}
\hline DNA names & Sequences (from $5 \square$ to $3 \square$ ) \\
\hline FAM-A $_{15}$ & FAM-AAAAAAAAAAAAAAA \\
\hline $\mathrm{FAM}-\mathrm{C}_{15}$ & FAM-CCCCCCCCCCCCCCC \\
\hline FAM-T $_{15}$ & FAM-TTTTTTTTTTTTTTT \\
\hline FAM-12mer & FAM- CACTGACCTGGG \\
\hline FAM-24-mer & FAM-ACGCATCTGTGAAGAGAACCTGGG \\
\hline FAM-A 30 & FAM-AAAAAAAAAAAAAAA AAAAAAAAAAAAAAA \\
\hline $\mathrm{AC}_{13} \mathrm{~A}$ & ACCCCCCCCCCCCCA \\
\hline $\mathrm{TC}_{13} \mathrm{~T}$ & ТСССССССССССССТ \\
\hline $\mathrm{CC}_{13} \mathrm{C}$ & CCCCCCCCCCCCCCC \\
\hline $\mathrm{GC}_{13} \mathrm{G}$ & GCCCCCCCCCCCCCG \\
\hline $\mathrm{AA}_{13} \mathrm{~A}$ & AAAAAAAAAAAAAAA \\
\hline $\mathrm{TA}_{13} \mathrm{~T}$ & TAAAAAAAAAAAAAT \\
\hline $\mathrm{CA}_{13} \mathrm{C}$ & CAAAAAAAAAAAAAC \\
\hline $\mathrm{GA}_{13} \mathrm{G}$ & GAAAAAAAAAAAAAG \\
\hline $\mathrm{AT}_{13} \mathrm{~A}$ & АTTTTTTTTTTTTTA \\
\hline $\mathrm{TT}_{13} \mathrm{~T}$ & тTTTTTтTTTTTTTT \\
\hline $\mathrm{CT}_{13} \mathrm{C}$ & СТTTTTTTTTTTTTC \\
\hline $\mathrm{GT}_{13} \mathrm{G}$ & GTTTTTTTTTTTTTG \\
\hline $\mathrm{AA}_{13} \mathrm{~T}$ & AAAAAAAAAAAAAAT \\
\hline $\mathrm{TA}_{13} \mathrm{~A}$ & TAAAAAAAAAAAAAA \\
\hline $\mathrm{AC}_{13} \mathrm{~T}$ & ACCCCССCСССCСCT \\
\hline $\mathrm{TC}_{13} \mathrm{~A}$ & TCCCCCCCCCCCCCA \\
\hline 9A3 & TTGTCGTTGCGTAAAAAAAAA \\
\hline 9 A5 & AAAAAAAAACCCAGGTTCTCT \\
\hline 9A3 $\mathrm{D}-\mathrm{SH}$ & TTGTCGTTGCGTAAAAAAAAA-SH \\
\hline 9A5 - $\mathrm{SH}$ & SH-AAAAAAAAACCCAGGTTCTCT \\
\hline Linker & ACGCAACGACAAAGAGAACCTGGG \\
\hline Mismatch DNA & ACGCATCGACAAAGAGAACCTGGG \\
\hline Control linker & CCCAGGTTCTCTTCACAGATGCGT \\
\hline
\end{tabular}


To understand if the low loading of $\mathrm{T}_{15}$ was a kinetic phenomenon, we measured the DNA adsorption kinetics. The data showed adsorption was finished in 2 min at $\mathrm{pH} 3.0$ for all the DNA sequences (Figure 2C). Therefore, the low capacity for FAM-T 15 cannot be explained by adsorption kinetics. We can also conclude from this experiment that high DNA loading speed was achieved at low $\mathrm{pH}$ even with non-thiolated DNA. ${ }^{16}$

To illustrate the $\mathrm{pH}$ effect on DNA adsorption to AuNPs, we performed gel electrophoresis experiments. After mixing FAM-A 15 with 13 nm AuNPs, pH was adjusted using citrate buffers from 37 and the samples were loaded into a gel (Figure 2D). A sharp red band was produced at $\mathrm{pH} 3$, indicating a homogeneous DNA loading on each AuNP and good colloidal stability. Neutral pH resulted in a purple smear. This can be explained by that only a small number of DNA being adsorbed at higher $\mathrm{pH}$, generating a relatively large distribution of adsorbed DNA. The lack of sufficient DNA coverage could also result in AuNP aggregation in the electric field, producing the purple smearing. Figure 2E shows the same gel imaged using the fluorescence mode under UV excitation. The nonadsorbed free DNA appears as white bands and AuNPs appear as black bands since they absorb UV light. Most of the DNAs were adsorbed at $\mathrm{pH} 3$, while more free DNAs were observed at higher $\mathrm{pH}$, consistent with our loading capacity data. AuNPs with DNA loaded at pH 3 migrated as a single band also indicating high stability of such DNA/AuNP conjugates without significant desorption during electrophoresis; otherwise smearing of the free DNA band should show up. 

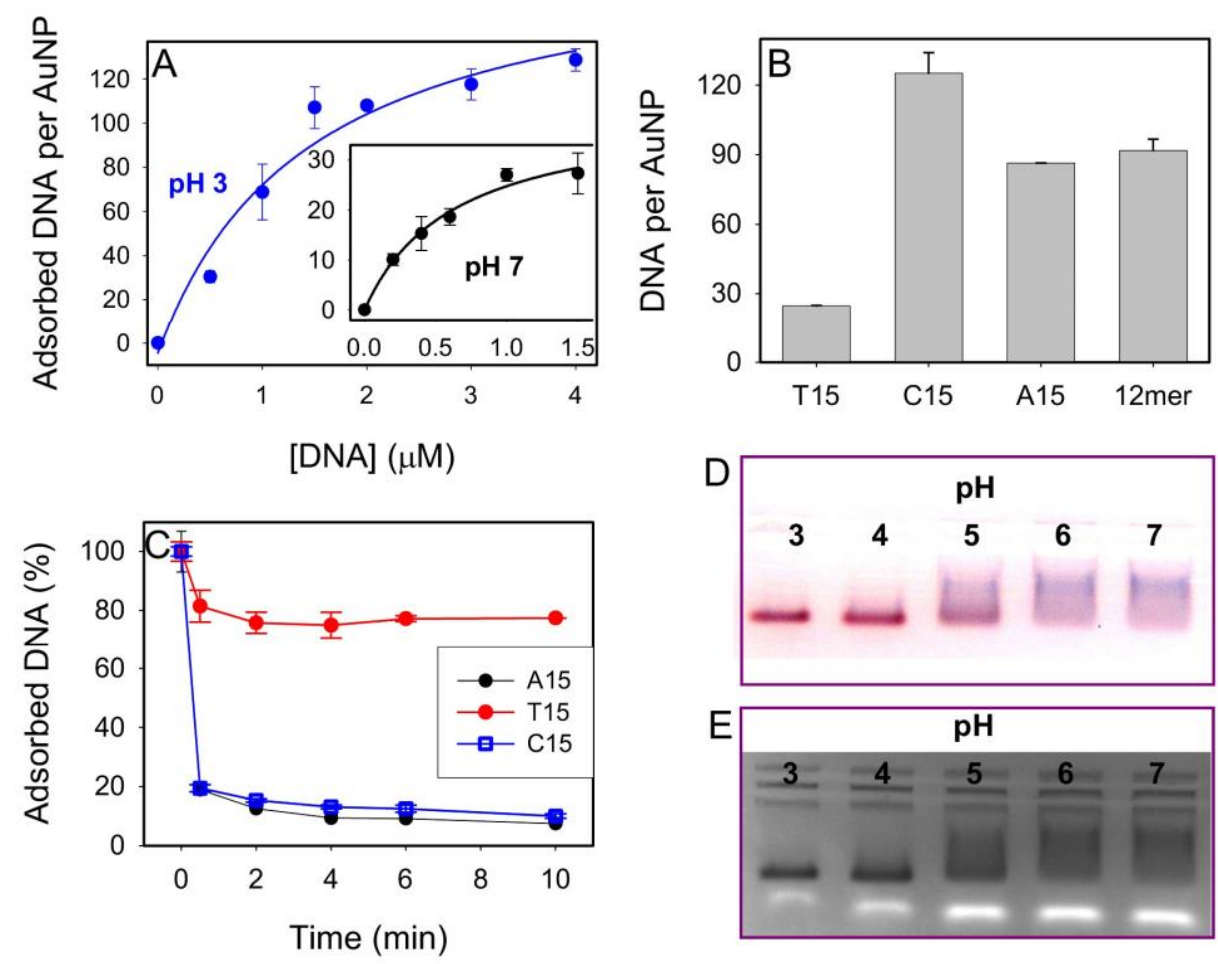

Figure 2. (A) Adsorption isotherm of FAM- $\mathrm{A}_{15}$ at $\mathrm{pH} 3$ or $\mathrm{pH} 7$ (inset). (B) DNA loading capacity of FAM-labeled $\mathrm{T}_{15}, \mathrm{C}_{15}$ and $\mathrm{A}_{15}$. (C) Kinetics of DNA adsorption monitored by fluorescence decreasing. Gel electrophoresis of FAM-A 15 adsorbed on $13 \mathrm{~nm}$ AuNPs at various $\mathrm{pH}$. The same gel was documented using a digital camera under ambient light (D) and in a darkroom under UV light excitation (E).

Adsorption of non-labeled DNA. In the above work, FAM-labeled DNAs were used to quantify DNA adsorption. Since these DNAs do not contain a thiol label, it is possible for adsorption to occur via the FAM label. To exclude the potential interference of the FAM label in the sequence effect studies, we employed a set of non-labeled 15-mer DNAs with their 13 internal nucleotides being $\mathrm{C}_{13}, \mathrm{~A}_{13}$ or $\mathrm{T}_{13}$. Their two ends contained all of the four DNA bases, yielding a total of twelve DNA sequences. The DNAs were respectively mixed with AuNPs at pH 3 and adsorbed DNA was quantified using SYBR Green I (Figure 3). All of the $\mathrm{T}_{13}$-containing DNAs showed low adsorption capacity, while $\mathrm{A}_{13}$ and $\mathrm{C}_{13}$ DNAs were adsorbed much more, consistent with the results using FAM-labeled DNA. Within each group, the DNAs ended with adenine had the highest loading capacity, consistent with the notion that 
adenine has a strong interaction with gold. ${ }^{23,24}$ Therefore, for DNA adsorption, each nucleotide contributes to the overall charge at low $\mathrm{pH}$, but the end nucleotides appear to be very important for the actual binding. The affinity was the highest for $\mathrm{A}$ and lowest for $\mathrm{T}$. We also compared the stability of AuNPs after centrifugation (insets of Figure 3 ), where $\mathrm{T}_{13}$ containing DNAs produced aggregates. This indicated a poor protection effect, consistent with their low loading capacity.

Our data indicate that high loading for non-thiolated DNA (e.g. 60-130) could be achieved as long as the DNA is rich in $\mathrm{A}$ and $\mathrm{C}$ and also terminated with these bases. Such a surprisingly high loading capacity is not in line with the conventional wisdom illustrated by the current wrapping model of nonthiolated DNA adsorption to AuNPs (Figure 1B). The maximal number of thiolated DNA adsorbed on each $13 \mathrm{~nm}$ AuNP is reported to be around 130, ${ }^{14,15}$ and our data for non-thiolated DNA could approach these values. One may propose multilayered adsorption due to protonation of DNA base at low $\mathrm{pH}$. However, the isotherm in Figure 2A failed to support such a possibility. In addition, our DNA loading was measured after repeated washing the AuNPs in a pH 7.6 buffer, where the DNAs became highly negatively charged and those failed to adsorb directly onto AuNP surface were washed away. Further DNA desorption experiments indicated that all of the DNAs were stably adsorbed (vide infra). Therefore, multi-layer adsorption cannot account for the observed high loading. We propose a new model shown in Figure 1C, where a large fraction of non-thiolated DNA strands are adsorbed on AuNP surface via just a single or a few terminal bases with an upright conformation, decreasing the footprint of each DNA and forming a dense DNA shell similar to thiolated DNAs. The real situation is likely to be more complicated and the surface may contain a diverse range of DNA arrangements and some could even be wrapping the AuNP as shown in Figure 1B. However, the average number of base adsorbed should be smaller than that achieved at neutral $\mathrm{pH}$. The data in Figure 3 also indicate that the adsorption capacity of non-thiolated DNA is a very strong function of DNA sequence. To achieve a high DNA density, it is useful to incorporate a block of poly-A sequences. Although thiolated DNA adsorption is also affected 
by DNA sequence, the final capacity difference is smaller. ${ }^{14}$ For adsorbed Trich DNA, the model in Figure $1 \mathrm{C}$ is unlikely to be true since the DNA density is quite low and it is reasonable for these DNAs to be in the wrapping model (Figure 1B) even at low $\mathrm{pH}$.

While this manuscript was in preparation, Fan and co-workers reported the conjugation of polyA terminated non-thiolated DNA to AuNPs at neutral $\mathrm{pH}$, where the poly-A segment displaced other nucleotides after 2-3 day incubation. ${ }^{41}$ In that system, a thermodynamic equilibrium might be reached after such a long time. In our method, a high DNA loading density was achieved at pH 3 after just a few minutes. Our high capacity suggests that not all the adenines are adsorbed and very likely that only the terminal base (or a few bases) anchors on AuNPs. For example, we achieved 130 A 15 DNA adsorption on each $13 \mathrm{~nm}$ AuNP. According to Fan's work, each $13 \mathrm{~nm}$ AuNP could adsorb close to 400 adenine bases from the DNA and thus we expect on average of three adenines to be adsorbed for each $\mathrm{A}_{15}$ DNA if the surface reaches a similar final adenine density. Our system in Figure 1C might be a kinetically stable state since thermodynamically it is reasonable for more adenine to adsorb from the same DNA and reduce the total number of adsorbed DNA to achieve multivalent binding. To test this, we first prepared the FAM-A ${ }_{15} / \mathrm{AuNP}$ conjugate at $\mathrm{pH} 3$ and then adjusted the $\mathrm{pH}$ with $50 \mathrm{mM}$ HEPES

( $\mathrm{pH}$ 7.6). After incubating the sample for 2 and 4 days at $\mathrm{pH} 7.6$, the DNA loading was reduced by $23 \%$ and $47 \%$, respectively. Therefore, the final loading is approaching to that when DNA was initially mixed with AuNPs at $\mathrm{pH} 7$ and it suggests that the wrapping model is thermodynamically more favorable at neutral $\mathrm{pH}$. 


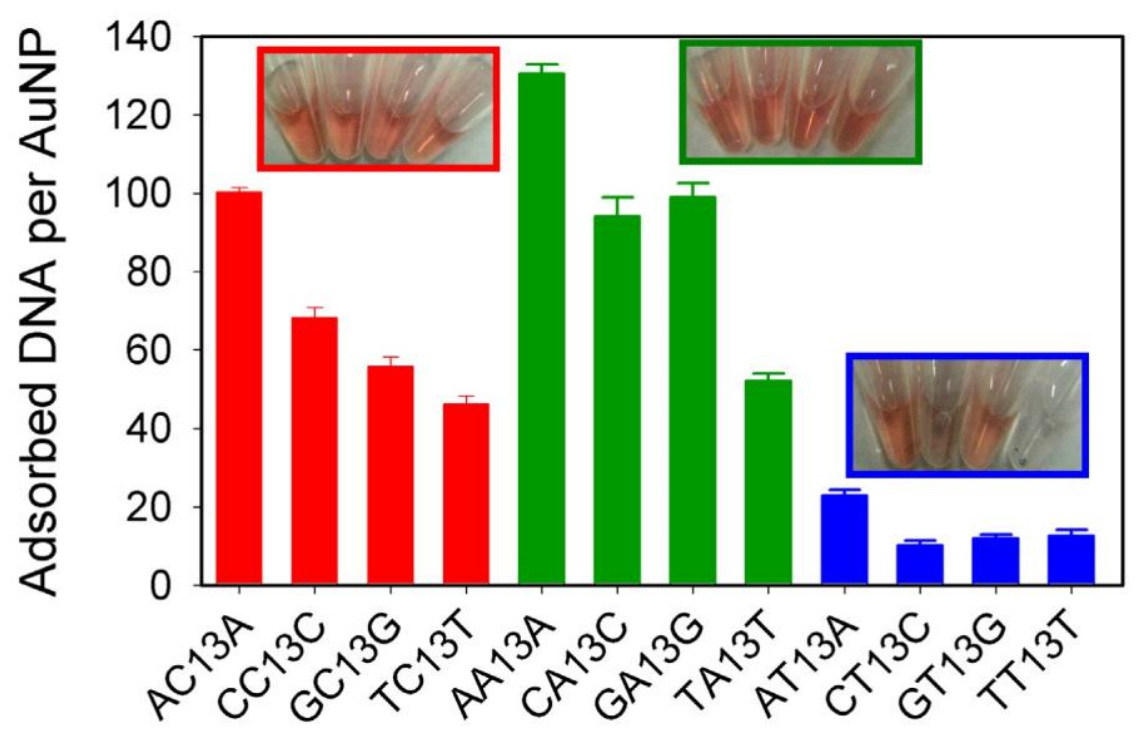

Figure 3. Non-labeled DNA adsorption onto AuNPs at low pH. The photographs of the AuNPs after centrifugation and re-dispersion in buffer show that the $\mathrm{T}_{13}$ containing DNAs exhibit poor protection for AuNPs. Insets show the color of AuNPs after centrifugation. The border color corresponds to the color of the bars.

Highly stable conjugates. Without a strong thiol anchor to AuNP surfaces, one would normally assume that DNA is only weakly adsorbed. We also showed above that $~ 50 \%$ DNA was desorbed if the sample is stored in $50 \mathrm{mM}$ HEPES after 4 days. Next we systematically test the conjugate stability. In Figure 4A, an increase of fluorescence indicating DNA desorption was observed for most of the samples. However, the desorption rate was extremely slow. Only FAM-T 15 desorbed by $2 \%$ while FAM-A 15 barely showed any desorption. $\mathrm{NaCl}$ has been previously shown to accelerate desorption for both thiolated DNA, ${ }^{42}$ and non-thiolated DNA loaded at neutral $\mathrm{pH} \cdot{ }^{40,43}$ Here we also tested nonthiolated DNA loaded at pH 3 (Figure 4B). We monitored the fluorescence increase of AuNPs loaded with FAM12mer DNA at various $\mathrm{NaCl}$ concentrations and indeed faster desorption was observed with higher $\mathrm{NaCl}$. Recent work on surface enhanced Raman scattering (SERS) has shown that $\mathrm{Cl}^{-}$could reduce the adsorption of DNA by binding to the AuNP surface and this competition may explain the effect of $\mathrm{NaCl}^{44}$ 
We further tested the thermal stability of the conjugate, where AuNPs with adsorbed FAM-A 15 was heated in a real time PCR thermocycler at $\mathrm{pH} 7.6$ and sample fluorescence was recorded from 10 to $95^{\circ} \mathrm{C}$ (Figure 4C). Little fluorescence increase was observed even at $95{ }^{\circ} \mathrm{C}$ (solid lines) and $\mathrm{NaCl}$ had little effects on thermal desorption, confirming high conjugate stability. Since all desorption experiments were performed at neutral $\mathrm{pH}$, DNA adsorbed at low $\mathrm{pH}$ remained highly stably adsorbed at neutral $\mathrm{pH}$. Our observation is consistent with the measurement of adsorption energies of DNA bases in other studies including temperature-programmed desorption. It has been reported that all of the bases are chemisorbed with a high energy (e.g. over $100 \mathrm{~kJ} / \mathrm{mol})$ with thymine adsorption being the weakest. ${ }^{45-47}$ While this energy is weaker than alkylthiol binding to gold (e.g. 120-160 kJ/mol), high stability could still be achieved.
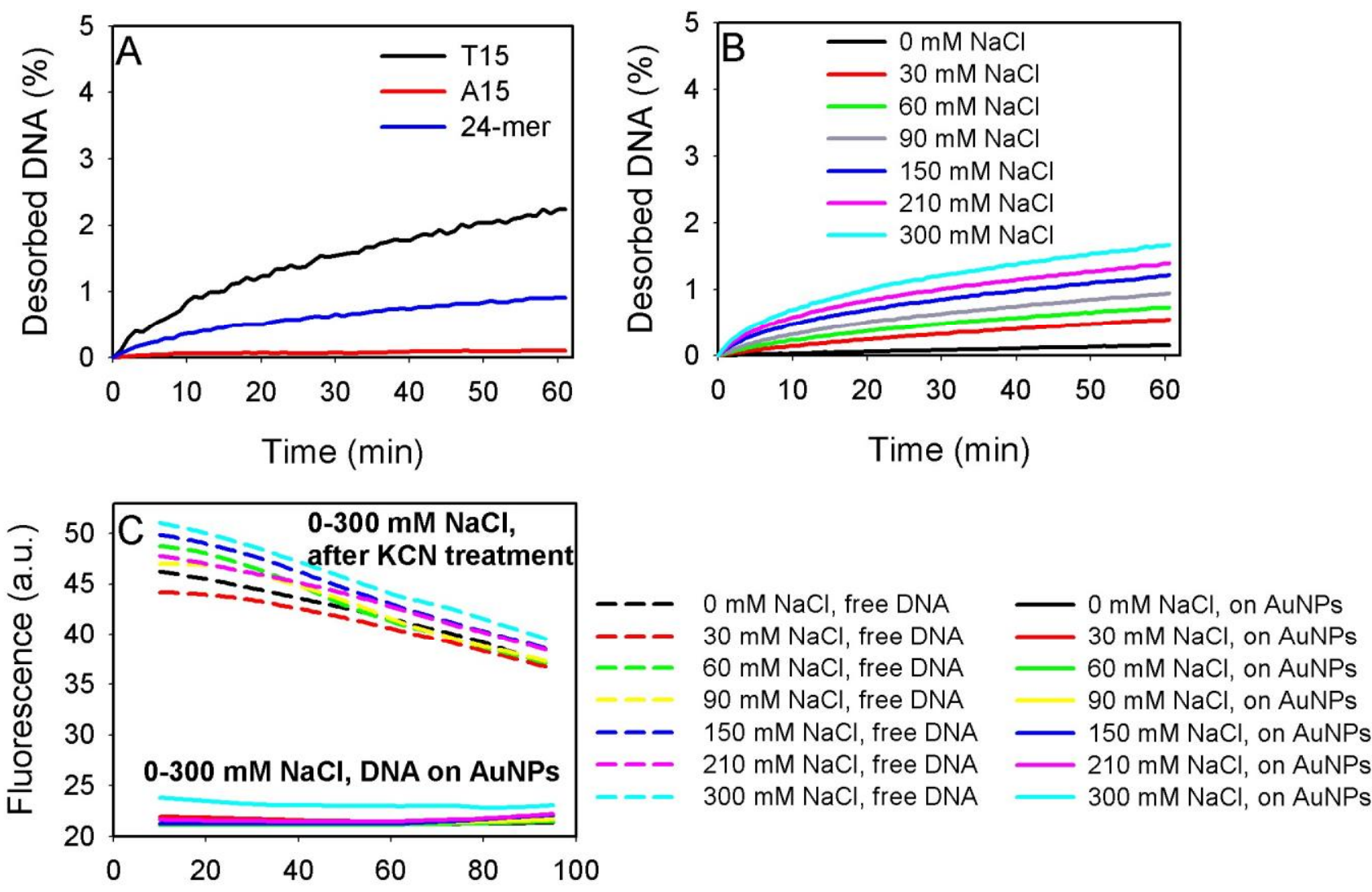

Temperature $\left({ }^{\circ} \mathrm{C}\right)$ 
Figure 4. DNA desorption studies. All the DNAs were adsorbed at $\mathrm{pH} 3.0$ followed by adjusting $\mathrm{pH}$ to 7.6 and removal of free DNA. (A) Desorption kinetics for various DNA sequences. (B) Desorption as a function of $\mathrm{NaCl}$ concentration for the 12-mer DNA. (C) FAM-A 15 thermal desorption in various $\mathrm{NaCl}$ concentrations. The free DNA without AuNPs was measured for comparison (dashed lines). Note that the instrument background reading was $\sim 20$ fluorescence units.

Application in AuNP separation. Given that non-thiolated DNA can be loaded with a similarly high density as its thiolated counterpart, the lack of a thiol also allows unique applications. For example, since AuNPs with DNA adsorbed at low pH migrate as a sharp band in gel (Figure 2D-E), it might be possible to use non-thiolated DNA for AuNP separation. To test this, we mixed AuNPs of various sizes with FAM-A 15 at $\mathrm{pH} 3$. As shown in Figure 5A, different sized AuNPs migrated at different rates and larger ones migrated more slowly. The bands are quite sharp and even $10 \mathrm{~nm}$ and $13 \mathrm{~nm}$ AuNPs can be separated, showing a high resolution. To confirm separation, the bands were excised and AuNPs were recovered and imaged by TEM. Figure 5B shows the mixed AuNPs, where all the three sizes were observed. After separation, only a single size was observed for each fraction (Figure 5C-E). It needs to be emphasized here that DNA adsorption at low $\mathrm{pH}$ is critical since at neutral $\mathrm{pH}$, only smeared bands were obtained (Figure 2E). While thiolated DNA might also achieve such separation, non-thiolated DNAs are more cost-effective and are more easily displaced by thiol containing compounds for downstream applications.

DNA-directed assembly and DNA detection. With the model in Figure 1C and a high DNA loading, we hypothesize that the adsorbed non-thiolated DNA may still be functional to undergo hybridization and DNA-directed assembly (Figure 6A). To test this, two DNA-AuNP conjugates were prepared with two DNAs (Table 1), respectively, each containing a nine-adenine spacer on the end to serve as an anchor on AuNP surfaces. Upon adding linker DNA strands, which are complementary to the two DNAs (except 
the nine-adenine spacer) adsorbed on AuNPs, to the mixture of the two conjugates, purple colored aggregates were formed (Figure 6B). Heating the sample to $70{ }^{\circ} \mathrm{C}$ produced a red color, which turned back to purple upon cooling. Therefore, even without a thiol label, adsorbed DNA was still able to undergo hybridization and DNA-directed assembly similar to thiolated DNA. Next, the aggregated AuNPs were gradually heated and their melting transitions were monitored using UV-vis spectroscopy. Meanwhile, the DNA-AuNP conjugates with the same DNA sequences but with thiol modification were used for comparison. For both samples, sharp melting transitions were observed at around the same temperature (Figure 6C). Since sharp melting transition is one of the most important characteristics of polyvalent DNA-AuNP nanostructures, ${ }^{17}$ non-thiolated DNA has demonstrated the capability of producing functional polyvalent nanomaterials as the thiolated DNA strands.

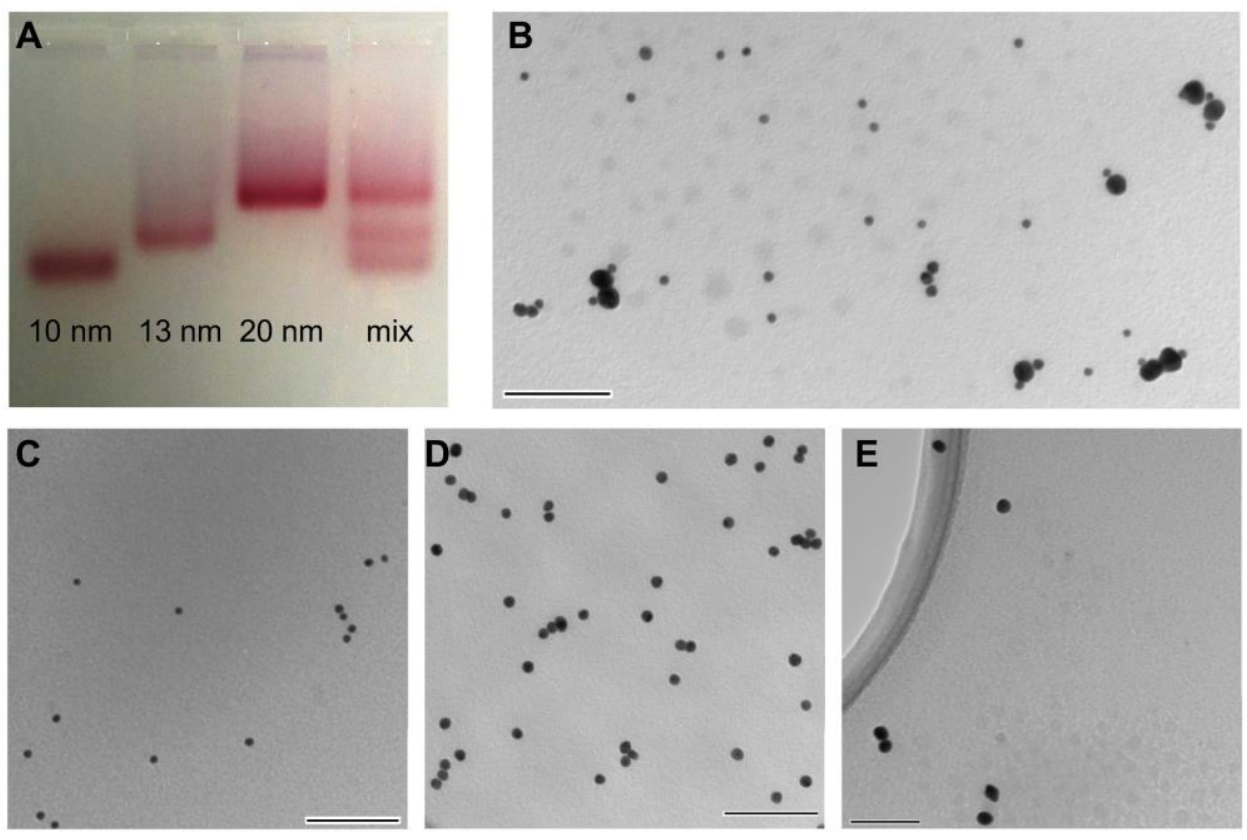

Figure 5. (A) Use of low pH loaded non-thiolated DNA for separating AuNPs by gel electrophoresis. TEM micrographs of mixed 10, 13, and $20 \mathrm{~nm}$ AuNPs (B) and after recovery from gel separation for the fastest band (C), the middle band (D) and the slowest band (E). 
Finally, we examined whether such non-thiolated DNA/AuNP conjugates could be used for specific DNA detection. To test the specificity, another linker DNA with a single base mismatch was used and indeed, a reduced $\mathrm{T}_{\mathrm{m}}$ was observed (Figure 6C, green curve). The sensitivity was enhanced with larger AuNPs $(50 \mathrm{~nm})$ since they have higher extinction coefficients than the $13 \mathrm{~nm}$ AuNPs. Normally, it is quite challenging to functionalize such large AuNPs even with thiolated DNA. We demonstrated herein that with the low $\mathrm{pH}$ loading method, non-thiolated DNA also produced stable conjugates. Spectroscopic measurements revealed that even 100 pM linker DNA could be detected (Figure 6D) and visual observation of such concentration of DNA was also possible (inset of Figure 6D).
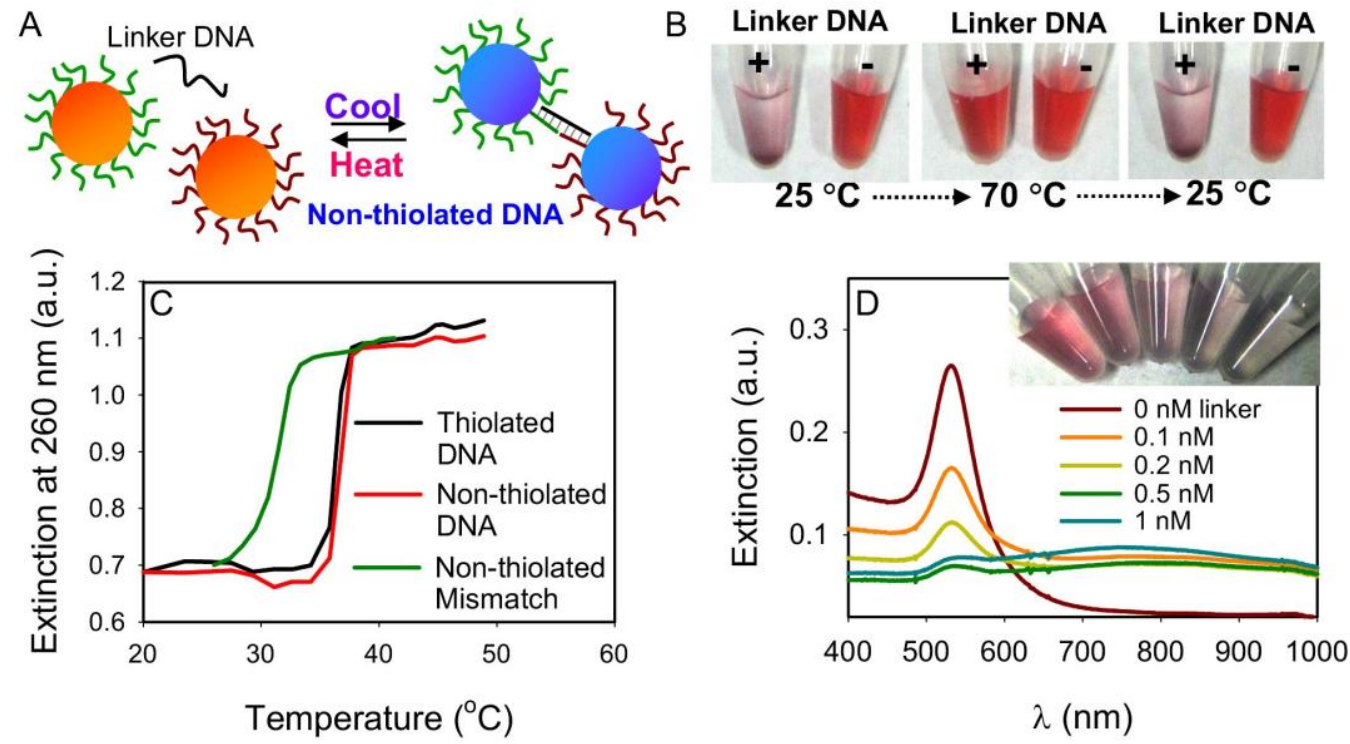

Figure 6. (A) Schematics of DNA-directed assembly involving only non-thiolated DNA functionalized AuNPs. (B) Reversible aggregation and melting of AuNPs with non-thiolated DNA. (C) Melting curves of DNA-linked AuNPs involving non-thiolated DNA (with and without mismatch) and in comparison with thiolated DNA. $\mathrm{NaCl}$ concentration $=25 \mathrm{mM}$. (D) UV-vis spectra of $50 \mathrm{~nm}$ AuNP with non-thiolated DNA for DNA detection. Inset: a photograph of the same samples with increasing linker DNA concentrations (0 to $1 \mathrm{nM}$ from left to right). 


\section{Conclusions}

In summary, we have prepared non-thiolated DNA functionalized polyvalent AuNPs using a low pH route and a number of important observations have been obtained in this work. At low $\mathrm{pH}$, the loading capacity for non-thiolated DNA can be comparable to thiolated DNA. Based on the high DNA density, we proposed a new model to explain the interaction between non-thiolated DNA with AuNPs. The densely loaded non-thiolated DNA not only provides high colloidal stability, but also maintains the full functions of both AuNP cores and DNA shell. The upright conformation adopted by the DNA strands allows for effective and specific molecular recognition. We established that DNA adsorption can be predicted by considering the following two factors. The first is the thymine and guanine content since they cannot be protonated at $\mathrm{pH}$ 3. Further reducing $\mathrm{pH}$ is unlikely to be feasible considering DNA depurination and cleavage reactions at low $\mathrm{pH}$. The second factor is the terminal bases that are responsible for adsorption. Even without a thiol label, the adsorbed DNA shows high capacity and stability, comparable to that of thiolated DNA. This new polyvalent DNA-AuNP conjugate can be applied for various applications including AuNP stabilization, electrophoretic separation, and DNAdirected assembly and detection. While non-thiolated DNA may not replace the established method using thiolated DNAs for all applications, especially when thymine-rich DNA strands are involved, it offers a more cost-effective alternative, considering that the thiol labeling can be $>90 \%$ of the total DNA synthesis cost. Finally, this work has broadened our fundamental understanding on the DNAAuNP interaction.

\section{Experimental Section}

Chemicals. All the DNA samples were purchased from Integrated DNA Technologies (Coralville, IA) and were purified by standard desalting. The DNA sequences and modifications are shown in Table 1 . 
$\mathrm{HAuCl}_{4}, \mathrm{KCN}$, bovine serum albumin (BSA), glutathione were from Sigma-Aldrich. AuNPs (13 nm) were synthesized based on the standard citrate reduction procedures and its concentration was estimated to be $\sim 10$ nM. ${ }^{12}$ AuNPs with other sizes were purchased from Ted Pella Inc. (Redding, CA). Ethanol, sodium hydroxide, and hydrochloric acid were purchased from VWR (Mississauga, ON). Sodium citrate, sodium chloride and 4-(2-hydroxyethyl) piperazine-1-ethanesulfonate (HEPES) were purchased from Mandel Scientific (Guelph, ON). Milli-Q water was used for all experiments.

Non-thiolated DNA attachment to AuNPs. To prepare the polyvalent DNA-AuNP conjugates, regardless of the DNA sequence or modification (Table 1), the general procedure includes four steps. First, a small volume (i.e., 1-3 $\mu \mathrm{L})$ of DNA stock solution (100 $\mu \mathrm{M}$ in $5 \mathrm{mM}$ HEPES buffer, pH 7.4) was added into $200 \mu \mathrm{L}$ of as-prepared AuNP solutions (10 nM) and mixed by a brief vortex. Second, a small volume of $500 \mathrm{mM} \mathrm{pH} 3$ citrate $\cdot \mathrm{HCl}$ buffer (final $10 \mathrm{mM}$ ) was added into the AuNP solution (e.g. $1 \mu \mathrm{L}$ buffer per $50 \mu \mathrm{L}$ AuNP solution). After a brief vortex, the sample was allowed to incubate at room temperature for $3 \mathrm{~min}$. Third, the $\mathrm{pH}$ of the AuNP solution was adjust back to neutral by adding $500 \mathrm{mM}$ HEPES buffer (pH 7.6, $3 \mu \mathrm{L}$ buffer per $50 \mu \mathrm{L}$ AuNP solution). The volume of added HEPES was about 3 times of the added pH 3 buffer in last step. The sample was allowed to incubate for another 5-10 min at room temperature. Last, the DNA-AuNP mixture was centrifuged at 15,000 rpm and the supernatant was removed. The pellet was washed 4-5 times with $5 \mathrm{mM}$ HEPES buffer and centrifugation to completely remove the free DNA strands. The final DNA-AuNP conjugate was redispersed in $5 \mathrm{mM}$ HEPES buffer for further use.

Electrophoretic separation of AuNPs. AuNPs with different size (10 nm, $13 \mathrm{~nm}$ and $20 \mathrm{~nm})$ were mixed together and functionalized with FAM-A 15 simultaneously with the abovementioned low $\mathrm{pH}$ method. After 5-10 min incubation at room temperature, the mixture was applied to $2.5 \%$ agarose gel for a 2 -hr electrophoresis under $50 \mathrm{~V}(5 \mathrm{~V} / \mathrm{cm})$. For comparison, the AuNPs with different sizes were functionalized with the same DNA separately and applied to the same electrophoresis together with the mixture, but in 
different lanes. For verification of the separated AuNPs with TEM, each AuNP band was cut out and grounded with a micropipette tip followed by socking in $20 \mathrm{mM}$ HEPES (pH 7.6) to recovery DNAAuNPs from the gel bands. The recovered AuNPs were applied on holey carbon coated copper TEM grids and imaged using a Philips CM-10 Transmission Electron Microscope.

DNA-directed assembly. AuNPs $(13 \mathrm{~nm})$ were functionalized with two 21-mer DNAs (9A3' and 9A5'), respectively, using the low-pH method with $\mathrm{pH} 3$ citrate buffer as described above. Afterwards, $50 \mu \mathrm{L}$ of each DNA-AuNP conjugate solution was transferred into a $0.6 \mathrm{~mL}$ microcentrifuge tube, and a final of $150 \mathrm{mM} \mathrm{NaCl}$ and $250 \mathrm{nM}$ linker DNA were added. For comparison, a reference was prepared containing the same amount of DNA-AuNPs and $\mathrm{NaCl}$, but instead of using linker DNA, a 24-mer control DNA non-complementary to either $9 \mathrm{~A}^{\prime}$ or $9 \mathrm{~A}^{\prime}$ was used in the reference tube. The mixture in the sample tube changed color to purple after only 10 min incubation at room temperature, which indicated forming the AuNP aggregates. The aggregates precipitated after 2 hours under $4{ }^{\circ} \mathrm{C}$ in the fridge. In contrast, the reference tube maintained the characteristic red color of dispersed AuNPs even after 20 hours in the fridge. The aggregates were imaged using the digital camera. To test the cooperative melting property of the DNA-directed assembly, the aggregates were centrifuged and gently dispersed into 3 volumes of $10 \mathrm{mM}$ HEPES buffer containing $25 \mathrm{mM} \mathrm{NaCl}$. Then, $200 \mu \mathrm{L}$ of each aggregate was transferred into a quartz micro-cuvette to measure the melting curves on a UV-Vis spectroscopy (Agilent $8453 \mathrm{~A})$, where the temperature was controlled by a circulating water bath. The actual temperature was recorded using a thermometer. The temperature was raised at a rate of $\sim 1{ }^{\circ} \mathrm{C} / \mathrm{min}$ with a holding time of $2 \mathrm{~min}$ at each temperature. The extinction value at $260 \mathrm{~nm}$ was plotted as a function of temperature. For comparison, thiolated DNA with the same sequence was also used to functionalize AuNPs and prepare DNA-linked AuNPs using the low pH method as above described. 


\section{Acknowledgements}

Funding for this work is from the University of Waterloo, the Canadian Foundation for Innovation,

Ontario Ministry of Research \& Innovation, Canadian Institutes of Health Research, and the Natural Sciences and Engineering Research Council (NSERC) of Canada.

Supporting Information. Additional methods, additional desorption data. This material is available free of charge via the Internet at http://pubs.acs.org.

\section{References:}

(1) Rosi, N. L.; Mirkin, C. A. Nanostructures in Biodiagnostics. Chem. Rev. 2005, 105, 1547-1562.

(2) Liu, J.; Cao, Z.; Lu, Y. Functional Nucleic Acid Sensors. Chem. Rev. 2009, 109, 1948-1998.

(3) Zhao, W.; Brook, M. A.; Li, Y. Design of Gold Nanoparticle-Based Colorimetric Biosensing Assays. ChemBioChem 2008, 9, 2363-2371.

(4) Li, D.; Song, S. P.; Fan, C. H. Target-Responsive Structural Switching for Nucleic Acid-Based Sensors. Acc. Chem. Res. 2010, 43, 631-641.

(5) Storhoff, J. J.; Mirkin, C. A. Programmed Materials Synthesis with DNA. Chem. Rev. 1999, 99, 1849-1862.

(6) Park, S. Y.; Lytton-Jean, A. K. R.; Lee, B.; Weigand, S.; Schatz, G. C.; Mirkin, C. A. DNAProgrammable Nanoparticle Crystallization. Nature 2008, 451, 553-556.

(7) Nykypanchuk, D.; Maye, M. M.; van der Lelie, D.; Gang, O. DNA-Guided Crystallization of Colloidal Nanoparticles. Nature 2008, 451, 549-552.

(8) Lin, C.; Liu, Y.; Yan, H. Designer DNA Nanoarchitectures. Biochemistry 2009, 48, 1663-1674.

(9) Katz, E.; Willner, I. Nanobiotechnology: Integrated Nanoparticle-Biomolecule Hybrid Systems: Synthesis, Properties, and Applications. Angew. Chem., Int. Ed. 2004, 43, 6042-6108. 
(10) Giljohann, D. A.; Seferos, D. S.; Daniel, W. L.; Massich, M. D.; Patel, P. C.; Mirkin, C. A. Gold Nanoparticles for Biology and Medicine. Angew. Chem. Int. Ed. 2010, 49, 3280-3294.

(11) Cutler, J. I.; Auyeung, E.; Mirkin, C. A. Spherical Nucleic Acids. J. Am. Chem. Soc. 2012, 134, 1376-1391.

(12) Storhoff, J. J.; Elghanian, R.; Mucic, R. C.; Mirkin, C. A.; Letsinger, R. L. One-Pot Colorimetric Differentiation of Polynucleotides with Single Base Imperfections Using Gold Nanoparticle Probes. J. Am. Chem. Soc. 1998, 120, 1959-1964.

(13) Demers, L. M.; Mirkin, C. A.; Mucic, R. C.; Reynolds, R. A., III; Letsinger, R. L.; Elghanian, R.; Viswanadham, G. A Fluorescence-Based Method for Determining the Surface Coverage and Hybridization Efficiency of Thiol-Capped Oligonucleotides Bound to Gold Thin Films and Nanoparticles. Anal. Chem. 2000, 72, 5535-5541.

(14) Hurst, S. J.; Lytton-Jean, A. K. R.; Mirkin, C. A. Maximizing DNA Loading on a Range of Gold Nanoparticle Sizes. Anal. Chem. 2006, 78, 8313-8318.

(15) Zu, Y.; Gao, Z. Facile and Controllable Loading of Single-Stranded DNA on Gold Nanoparticles. Anal. Chem. 2009, 81, 8523-8528.

(16) Zhang, X.; Servos, M. R.; Liu, J. Instantaneous and Quantitative Functionalization of Gold Nanoparticles with Thiolated DNA Using a pH-Assisted and Surfactant-Free Route. J. Am. Chem. Soc. 2012, 134, 7266-7269.

(17) Jin, R.; Wu, G.; Li, Z.; Mirkin, C. A.; Schatz, G. C. What Controls the Melting Properties of DNA-Linked Gold Nanoparticle Assemblies? J. Am. Chem. Soc. 2003, 125, 1643-1654.

(18) Lytton-Jean, A. K. R.; Mirkin, C. A. A Thermodynamic Investigation into the Binding Properties of DNA Functionalized Gold Nanoparticle Probes and Molecular Fluorophore Probes. J. Am. Chem. Soc. 2005, 127, 12754-12755.

(19) Seferos, D. S.; Prigodich, A. E.; Giljohann, D. A.; Patel, P. C.; Mirkin, C. A. Polyvalent DNA 
Nanoparticle Conjugates Stabilize Nucleic Acids. Nano Lett. 2009, 9, 308-311.

(20) Giljohann, D. A.; Seferos, D. S.; Patel, P. C.; Millstone, J. E.; Rosi, N. L.; Mirkin, C. A.

Oligonucleotide Loading Determines Cellular Uptake of DNA-Modified Gold Nanoparticles. Nano Lett. 2007, 7, 3818-3821.

(21) Zaki, A.; Dave, N.; Liu, J. Amplifying the Macromolecular Crowding Effect Using Nanoparticles. J. Am. Chem. Soc. 2012, 134, 35-38.

(22) Li, H.; Rothberg, L. J. Label-Free Colorimetric Detection of Specific Sequences in Genomic DNA Amplified by the Polymerase Chain Reaction. J. Am. Chem. Soc. 2004, 126, 10958-10961.

(23) Storhoff, J. J.; Elghanian, R.; Mirkin, C. A.; Letsinger, R. L. Sequence-Dependent Stability of DNA-Modified Gold Nanoparticles. Langmuir 2002, 18, 6666-6670.

(24) Kimura-Suda, H.; Petrovykh, D. Y.; Tarlov, M. J.; Whitman, L. J. Base-Dependent Competitive Adsorption of Single-Stranded DNA on Gold. J. Am. Chem. Soc. 2003, 125, 9014-9015.

(25) Herne, T. M.; Tarlov, M. J. Characterization of DNA Probes Immobilized on Gold Surfaces. J. Am. Chem. Soc. 1997, 119, 8916-8920.

(26) Sandstrom, P.; Boncheva, M.; Akerman, B. Nonspecific and Thiol-Specific Binding of DNA to Gold Nanoparticles. Langmuir 2003, 19, 7537-7543.

(27) Li, H.; Liang, R.; Turner, D. H.; Rothberg, L. J.; Duan, S. Selective Quenching of Fluorescence from Unbound Oligonucleotides by Gold Nanoparticles as a Probe of RNA Structure. RNA 2007, 13, 2034-2041.

(28) Zhang, J.; Wang, L. H.; Pan, D.; Song, S. P.; Boey, F. Y. C.; Zhang, H.; Fan, C. H. Visual Cocaine Detection with Gold Nanoparticles and Rationally Engineered Aptamer Structures. Small 2008, 4, 1196-1200.

(29) Wang, Z.; Lee, J. H.; Lu, Y. Label-Free Colorimetric Detection of Lead Ions with a Nanomolar Detection Limit and Tunable Dynamic Range by Using Gold Nanoparticles and Dnazyme. Adv. Mater. 2008, 20, 3263-3267. 
(30) Wang, W. J.; Chen, C. L.; Qian, M. X.; Zhao, X. S. Aptamer Biosensor for Protein Detection Using Gold Nanoparticles. Anal. Biochem. 2008, 373, 213-219.

(31) Wei, H.; Li, B.; Li, J.; Dong, S.; Wang, E. Dnazyme-Based Colorimetric Sensing of Lead $\left(\mathrm{Pb}^{2+}\right)$ Using Unmodified Gold Nanoparticle Probes. Nanotechnology 2008, 19, 095501.

(32) Wang, L.; Liu, X.; Hu, X.; Song, S.; Fan, C. Unmodified Gold Nanoparticles as a Colorimetric Probe for Potassium DNA Aptamers. Chem. Comm. 2006, 3780-3782.

(33) Wang, J.; Wang, L. H.; Liu, X. F.; Liang, Z. Q.; Song, S. P.; Li, W. X.; Li, G. X.; Fan, C. H. A Gold Nanoparticle-Based Aptamer Target Binding Readout for ATP Assay. Adv. Mater. 2007, 19, 3943-3946.

(34) Zheng, X.; Liu, Q.; Jing, C.; Li, Y.; Li, D.; Luo, W.; Wen, Y.; He, Y.; Huang, Q.; Long, Y.-T.;

Fan, C. Catalytic Gold Nanoparticles for Nanoplasmonic Detection of DNA Hybridization. Angew. Chem., Int. Ed. 2011, 50, 11994-11998.

(35) Li, H. K.; Huang, J. H.; Lv, J. H.; An, H. J.; Zhang, X. D.; Zhang, Z. Z.; Fan, C. H.; Hu, J. Nanoparticle PCR: Nanogold-Assisted PCR with Enhanced Specificity. Angew. Chem. Int. Ed. 2005, 44, 5100-5103.

(36) Park, K. S.; Kim, M. I.; Cho, D.-Y.; Park, H. G. Label-Free Colorimetric Detection of Nucleic Acids Based on Target-Induced Shielding against the Peroxidase-Mimicking Activity of Magnetic Nanoparticles. Small 2011, 7, 1521-1525.

(37) Wang, Z.; Zhang, J.; Ekman, J. M.; Kenis, P. J. A.; Lu, Y. DNA-Mediated Control of Metal Nanoparticle Shape: One-Pot Synthesis and Cellular Uptake of Highly Stable and Functional Gold Nanoflowers. Nano Lett. 2010, 10, 1886-1891.

(38) Xu, L.; Zhu, Y.; Ma, W.; Chen, W.; Liu, L.; Kuang, H.; Wang, L.; Xu, C. New Synthesis Strategy for DNA Functional Gold Nanoparticles. J. Phys. Chem. C 2011, 115, 3243-3249. 
(39) Rosi, N. L.; Giljohann, D. A.; Thaxton, C. S.; Lytton-Jean, A. K. R.; Han, M. S.; Mirkin, C. A. Oligonucleotide-Modified Gold Nanoparticles for Intracellular Gene Regulation. Science 2006, 312, 1027-1030.

(40) Zhang, X.; Servos, M. R.; Liu, J. Surface Science of DNA Adsorption onto Citrate-Capped Gold Nanoparticles. Langmuir 2012, 28, 3896-3902.

(41) Pei, H.; Li, F.; Wan, Y.; Wei, M.; Liu, H.; Su, Y.; Chen, N.; Huang, Q.; Fan, C. Designed Diblock Oligonucleotide for the Synthesis of Spatially Isolated and Highly Hybridizable Functionalization of DNA-Gold Nanoparticle Nanoconjugates. J. Am. Chem. Soc. 2012, 134, 1187611879.

(42) Bhatt, N.; Huang, P.-J. J.; Dave, N.; Liu, J. Dissociation and Degradation of Thiol-Modified DNA on Gold Nanoparticles in Aqueous and Organic Solvents. Langmuir 2011, 27, 6132-6137.

(43) Liu, J. Adsorption of DNA onto Gold Nanoparticles and Graphene Oxide: Surface Science and Applications. Phys. Chem. Chem. Phys. 2012, 14, 10485-10496.

(44) Bell, S. E. J.; Sirimuthu, N. M. S. Surface-Enhanced Raman Spectroscopy (SERS) for SubMicromolar Detection of DNA/RNA Mononucleotides. J. Am. Chem. Soc. 2006, 128, 1558015581.

(45) Demers, L. M.; Oestblom, M.; Zhang, H.; Jang, N.-H.; Liedberg, B.; Mirkin, C. A. Thermal Desorption Behavior and Binding Properties of DNA Bases and Nucleosides on Gold. J. Am. Chem. Soc. 2002, 124, 11248-11249.

(46) Ostblom, M.; Liedberg, B.; Demers, L. M.; Mirkin, C. A. On the Structure and Desorption Dynamics of DNA Bases Adsorbed on Gold: A Temperature-Programmed Study. J. Phys. Chem. B 2005, 109, 15150-15160.

(47) Boland, T.; Ratner, B. D. Direct Measurement of Hydrogen Bonding in DNA Nucleotide Bases by Atomic Force Microscopy. Proc. Natl. Acad. Sci. U.S.A. 1995, 92, 5297-5301. 
